\title{
Estimation of Vitamin C in Carrot Before Cooking and After Cooking
}

\author{
Md. Iqbal Hussain", Amir Hamza, M. A. Rashid \\ Department of Applied Chemistry and Chemical Technology, Islamic University, Kushtia, Bangladesh
}

Email address:

iqba10557@yahoo.com (Md. I. Hussain)

${ }^{*}$ Corresponding author

\section{To cite this article:}

Md. Iqbal Hussain, Amir Hamza, M. A. Rashid. Estimation of Vitamin C in Carrot Before Cooking and After Cooking. Journal of Food and Nutrition Sciences. Vol. 4, No. 4, 2016, pp. 108-112. doi: 10.11648/j.jfns.20160404.16

Received: February 21, 2016; Accepted: February 28, 2016; Published: July 21, 2016

\begin{abstract}
The change of vitamin C content of fresh and cooked carrot (Daucus carota) is a subject of considerable concern and investigation. In the last few years, some research is showing the changes of the vitamin $\mathrm{C}$ content of fresh and cooked foods. This study has been aimed to present the estimation vitamin $\mathrm{C}$ content of fresh and cooked carrot. Vitamin loss can be induced by a number of factors. Obviously, losses of vitamins depend on cooking time, temperature, and cooking method. Some vitamins are quite heat-stable, whereas others are heat-labile. Many other factors than heat can destroy (some) vitamins, such as: solubility in water, exposure to air (oxidation), exposure to light (UVs), heat, acid and alkaline solutions, storage losses, etc. An essential nutrient found mainly in vegetables. The body requires vitamin $\mathrm{C}$ to form and maintain bones, blood vessels, and skin. Vitamin $\mathrm{C}$ is also known as ascorbic acid. Vitamin $\mathrm{C}$ is a water-soluble vitamin. It must be replenished daily. Vitamin $\mathrm{C}$ helps make collagen, a protein needed to develop and maintain healthy teeth, bones, gums, cartilage, vertebrae discs, joint linings, skin and blood vessels etc. From our study, we observed that vitamin $\mathrm{C}$ contains $5.8 \%$ in uncooked carrot and after cooking the content of vitamin $\mathrm{C}$ is $2.6 \%$. From the study, we can say that the content of vitamin $\mathrm{C}$ decreases with respect to cooking. So if we heat foods for long time then the content of vitamin $\mathrm{C}$ becomes low.
\end{abstract}

Keywords: Cooking, Vitamin C, Carrot, Daucus carota

\section{Introduction}

The carrot is generally orange in color. It has a crunchy texture when fresh. The edible part of a carrot is although the greens are sometimes eaten as well. It is a domestic type of the Daucus carota, native to southwestern Asia and Europe. The domestic carrot has been selectively bred for its greatly enlarged and more palatable, less woody-textured edible taproot. Approximately half were grown in China. Carrots are broadly used in the preparation of salads. This has produced the familiar garden vegetable [1].

Vegetables are rich sources of essential vitamins, minerals, fibers and disease-fighting phytochemicals which the human body needs to maintain good health [2]. Some vegetables can be in use raw but most are normally suitable for eating before being consumed. Generally, preparations of vegetables at home are based on taste preference and convenience rather than retention of nutrient and health-promoting compounds
[3]. Report has publicized that consumption of diets rich in vegetables and fruits protect the human body from chronic degenerative diseases. Vitamin $\mathrm{C}$, also known as ascorbic acid, is a water-soluble vitamin found in fruits and vegetables. It is an antioxidant that is very essential for human nutrition and proper functioning of the body. Vitamin $\mathrm{C}$ cannot be synthesized in human body, so it is an essential dietary constituent. Vitamin $\mathrm{C}$ is instrumental in neutralizing free radicals, which are harmful to the body, assimilation of iron, healing of wounds, helps to make collagen, which aids the skin, defense against bacterial and viral infection. Lack of vitamin $\mathrm{C}$ in human can lead scurvy disease whose symptoms include in gums and skin, loosening of the teeth, joint pains and exhaustion. Many vegetables contain vitamin $\mathrm{C}$, but in high temperature vitamin $\mathrm{C}$ can be destroyed totally. At high temperature vitamin $\mathrm{C}$ reacts and oxidizes in the presence of sunlight and oxygen in air. [4].

Vitamins are the best micronutrients that play important roles in the human nutrition. Some might be regarded 
sensitive to processing and preservation and thus might be reduced to a great extent [5]. Some vitamins are water soluble and some are fat soluble and depending on their solubility in different media they might act differently. The excess consumption of water soluble vitamins might not cause problems due to their solubility in water and can be removed from the body easily however this might not be the case for fat soluble vitamins. The effects of light, heat, metals, $\mathrm{pH}$, oxygen, enzymes and moisture on the retention and decomposition of vitamins are important and have been studied to a great extent. The effect of cooking of food and decomposition of vitamins depending on the degree and time of heat treatment and factors involved has been studied in great detail. In general water soluble vitamins are more sensitive than the fat soluble ones [6].

Usually vegetables have considerable amounts of vitamins and generally they have little protein or fat and low calorie content. Vegetables have high fiber content and they also remain natural color pigments. Phytochemicals which are powerful antioxidants and also prominent in vegetables, help in cardiovascular diseases and prostrate cancer carrots has also been limited to the preparation of soup, stew and salad. The objectives ofthis research work were to select one variety of processed tomato juices through sensory evaluation as well as formulate and determine the physicochemical properties and sensory qualities of cocktail juices from tomatoes, oranges and carrots [7].

Except human and other primates, most of the phylogenetically higher animals can synthesize vitamin $\mathrm{C}(L-$ ascorbate). More than $90 \%$ of the vitamin $\mathrm{C}$ in human diets is supplied by fruits and vegetables (including potatoes). Vitamin $C$ is defined as the generic term for all compounds exhibiting the biological activity of $L$-ascorbic acid. Ascorbic acid is the principal biologically active form but $L$ dehydroascorbic acid, an oxidation product, also exhibits biological activity. Vitamin $\mathrm{C}$ is required for the prevention of scurvy and maintenance of healthy skin, gums and blood vessels. It functions in collagen ormation, absorption of inorganic iron, reduction of plasma cholesterol level, inhibition of nitrosoamine formation, enhancement of the immune system, and reaction with singlet oxygen and other free radicals. As an antioxidant, it reportedly reduces the risk of arteriosclerosis, cardiovascular diseases and some forms of cancer. The consumption of fruit juices and vegetables are beneficial and the health effects of fruits are ascribed, in part to ascorbic acid, a natural antioxidant which may inhibit the development of major clinical conditions including cardiovascular diseases and cancer. Present study was to relate the content of ascorbic acid some local fruits and vegetables [8].

The debate about the nutritional superiority of organically and conventionally grown products has been athering momentum for some time especially in developed countries. The debate has cut across different agricultural produce animal products inclusive. Organic products are those products, which are produced under controlled cultivation conditions with the provisions of the regulation on organic farming. Requirements for organic certification vary from country to country and generally involve a set of production standards for growing, storage, processing, packaging and shipping. Organic certification is intended to assure quality and prevent fraud. There have been many reasons why the demand for organic produce has been growing as reported by other findings. Magkos and Zampelas reported that one of the primary reasons for purchasing organically grown produce is the perception that they are more nutritious than the conventional produce. They further reported there are only few well-controlled studies that are capable of making valid comparison and therefore, compilation of results is difficult and generalization of the conclusions should be made with caution. It is evident that with people's growing awareness of health and the environment, public interest is increasing lyfocusing on the problem of the quality of foods and that considerable attention is being paid in organically grown produce considering the fact that the conventionally grown products have always be already there. Meier-Ploeger as eported by Woese et al. In the United Kingdom, there is a growing demand in organic foods though the market can only provide $30 \%$ of the organic food consumed which means the rest needs to be brought from more developed market abroad. Increased numbers of farmers are turning to organic production but their farms must undergo a conversion period before they can obtain the coveted organic certification. Although the interest in the organically grown foods has been on increase, there have not been substantial studies to substantiate convincingly that organically grown foods are nutritionally superior to their conventionally grown counterparts. The debate is even further intensified by the facts that for some of the studies that have been carried out to compare the nutritive value between organically and conventionally grown produce, there have been some conflicting findings regarding the nutritive contents in the organic and conventional produce. It is this dilemma of insufficient information on the nutritive value of conventionally and rganically grown foods that calls for renewed efforts in further nutrient determination so that future generalization of conclusions about the nutritive value of these two groups can be made from substantial amount of sources [9].

\section{Methods \& Materials}

In this research at first, fresh sample (Carrot) were taken for experiment and vitamin $\mathrm{C}$ content content was estimated. The following materials and methods are used for the estimation of vitamin $\mathrm{C}$ in carrot.

\subsection{Materials}

- Carrot

- Conical flask

- Burette

- Pipette

- Beaker

- Dropper 
- Distilled Water

- Filter Paper

- Glass Rod

- Volumetric Flask

- Ascorbic Acid

- Metaphosphoric Acetic Acid

- 2, 6-Dichlorophenol Indophenols Sodium salt solution

\subsection{Methods}

Vitamin C content was determined according to the Association of Official Analytical Chemists (AOAC) Official Method 985.33 (2, 6-dichloroindophenol titrimetric method) [10]. Vitamin C content is expressed as $\mathrm{mg} / 100 \mathrm{~g}$ fresh weight.

\subsubsection{Preparation of Reagents}

- Dye solution: $50 \mathrm{mg}$ of 2, 6-dichlorophenol indophenols and $52.5 \mathrm{mg}$ of sodium bicarbonate were dissolved in distilled water and made upto $250 \mathrm{ml}$. the solution was filtered.

- $3 \%$ metaphosphoric acid reagent: $7.5 \mathrm{gm}$ of metaphosphoric acid was dissolved in $20 \mathrm{ml}$. of acetic acid and made upto $250 \mathrm{ml}$. with distilled water.

- Standard vitamin C solution $(.1 \mathrm{mg} / \mathrm{ml}$.): $10 \mathrm{mg}$ of pure vitamin $\mathrm{C}$ was dissolved in 3\% metaphosphoric acid and made upto $100 \mathrm{ml}$. with $3 \%$ metaphosphoric acid.

\subsubsection{Preparation of Raw Carrot Solution}

At first $10 \mathrm{gm}$ of raw carrot is taken into a mortar and pasted it by pastel. By adding sufficient distilled water make it into a solution. Transfer this sample solution in a $100 \mathrm{ml}$ volumetric flask and make up to mark by $3 \%$ metaphosphoric acid. Then the solution was filtered and the filtrate solution was known as unknown sample for raw carrot.

\subsubsection{Blank Titration}

For blank titration at first $10 \mathrm{ml}$ of the metaphosphoric acetic acid T. S plus a volume of water equal to the volume of dichlorophenol indophenols sodium salt solution used in titrating the ascorbic acid solution. The burette reading was written exactly.

\subsubsection{Estimation of the Amount of Vitamin $C$ in the Given Raw Carrot}

At first $10 \mathrm{ml}$ of prepared raw carrot solution was taken into a $250 \mathrm{ml}$ conical flask. Then titrated with dichlorophenol indophenols sodium salt solution from burette until a distinct light pink color persists for at least 5 second. The exact burette reading was noted.

\subsubsection{Titration of Known Sample (Standardization of Dichlorophenol Indophenols Sodium Salt Solution)}

$10 \mathrm{ml}$ of standard vitamin $\mathrm{C}$ solution is taken in a conical flask and titrated it with prepared dye from burette until a distinct light pink color. Noted the exact burette reading.

\subsubsection{Estimation of the Amount of Vitamin-C (Ascorbic Acid) in the Given Cooked Carrot}

At first $10 \mathrm{~g}$ of raw carrot is then cooked by heating in a pan. After the heating the cooked carrot is taken into a mortar and pasted it well by adding sufficient water to make into solution. Transfer this sample in a $100 \mathrm{ml}$ volumetric flask and make up to mark by $3 \%$ metaphosphoric acid. Then $10 \mathrm{ml}$ of this supplied solution is taken into a conical flask and titrate it with dye until a distinct light pink color and the exact burette reading was noted.

\section{Calculation}

\subsection{Experimental Data: (For Raw Carrot Sample)}

Table 1. Titration of unknown supplied sample (Raw carrot solution) with dichlorophenol indophenol sodium salt solution.

\begin{tabular}{llllll}
\hline \multirow{2}{*}{ No. of obs. } & \multirow{2}{*}{$\begin{array}{l}\text { Volume of unknown sample (Raw carrot) } \\
\text { solution in }(\mathbf{m l})\end{array}$} & \multicolumn{3}{|c}{ Burette reading of dye solution in (ml) } \\
\cline { 3 - 5 } & 10 & Initial $(\mathbf{m l})$ & Final $(\mathbf{m l})$ & Diff. (ml) \\
\hline 1 & 10 & 0 & 1.2 & 1.2 \\
2 & 10 & 1.2 & 2.4 & 1.2 \\
3 & & 2.4 & 3.6 & 1.2 \\
\hline
\end{tabular}

Table 2. Titration of known vitamin C solution with dichlorophenol indophenol sodium salt solution.

\begin{tabular}{lllll}
\hline \multirow{2}{*}{ No. of obs. } & \multicolumn{2}{l}{$\begin{array}{l}\text { Volume of supplied sample (vitamin C) } \\
\text { solution in }(\mathbf{m l})\end{array}$} & \multicolumn{4}{c}{ Burette reading of dye solution in (ml) } \\
\cline { 3 - 5 } & 10 & Initial $(\mathbf{m l})$ & Final $(\mathbf{m l})$ & Diff. (ml) \\
\hline 1 & 10 & 0 & 19 & 19 \\
2 & 10 & 19 & 38 & 19 \\
3
\end{tabular}

Table 3. Blank titration for raw carrot solution with dichlorophenol indophenol sodium salt solution.

\begin{tabular}{llllll}
\hline \multirow{2}{*}{ No. of obs. } & \multicolumn{2}{l}{$\begin{array}{l}\text { Volume of metaphosphoric acetic acid } \\
\text { solution in }(\mathbf{m l})\end{array}$} & \multicolumn{3}{c}{ Burette reading of dye solution in (ml) } \\
\cline { 3 - 5 } & 10 & Initial $(\mathbf{m l})$ & Final $(\mathbf{m l})$ & Diff. (ml) \\
\hline 1 & 10 & 0 & 0.1 & 0.1 & 0.1 \\
2 & 10 & 0.1 & 0.2 & 0.1 \\
\hline
\end{tabular}

Experimental data: (For cooked carrot sample) 
Table 4. Titration of cooked carrot solution with dichlorophenol indophenol sodium salt solution.

\begin{tabular}{|c|c|c|c|c|c|}
\hline \multirow{2}{*}{ No. of obs. } & \multirow{2}{*}{ Volume of cooked carrot solution in (ml) } & \multicolumn{3}{|c|}{ Burette reading of dye solution in $(\mathrm{ml})$} & \multirow{2}{*}{ Mean volume of dye solution ( $\mathrm{ml}$ ) } \\
\hline & & Initial (ml) & Final (ml) & Diff. (ml) & \\
\hline 1 & 10 & 0 & 0.6 & 0.6 & \multirow{3}{*}{0.6} \\
\hline 2 & 10 & 0.6 & 0.12 & 0.6 & \\
\hline 3 & 10 & 0.12 & 0.18 & 0.6 & \\
\hline
\end{tabular}

Table 5. Blank titration for cooked carrot solution with dichlorophenol indophenol sodium salt solution.

\begin{tabular}{llllll}
\hline \multirow{2}{*}{ No. of obs. } & Volume of metaphosphoric acetic acid & \multicolumn{3}{l}{ Burette reading of dye solution in $(\mathbf{m l})$} & \multirow{2}{*}{ Mean volume of dye solution (ml) } \\
\cline { 3 - 5 } & solution in $(\mathbf{m l})$ & Initial $(\mathbf{m l})$ & Final $(\mathbf{m l})$ & Diff. $(\mathbf{m l})$ & \\
\hline 1 & 10 & 0 & 0.1 & 0.1 & 0.1 \\
2 & 10 & 0.1 & 0.2 & 0.1 & \\
3 & 10 & 0.2 & 0.3 & 0.1 & \\
\hline
\end{tabular}

For raw Carrot sample:

Weight of raw carrot sample $=10 \mathrm{gm}$ (taken)

Weight of supplied vitamin $\mathrm{C}$ sample $=0.1 \mathrm{mg} / \mathrm{ml}$

Total volume of raw carrot sample $=100 \mathrm{ml}$

For known sample:

$1 \mathrm{ml}$ vitamin $\mathrm{C}$ solution contains $=0.1 \mathrm{mg}$ vitamin $\mathrm{C}$

$10 \mathrm{ml}$ vitamin $\mathrm{C}$ solution contains $=1 \mathrm{mg}$ vitamin $\mathrm{C}$

Volume of required dye solution= Known sample titration

- Blank titration $=19-0.1=18.9 \mathrm{ml}$

$18.9 \mathrm{ml}$ dye solution is required for $=1 \mathrm{mg}$ vitamin $\mathrm{C}$

$1 \mathrm{ml}$ dye solution is required for $0.05291 \mathrm{mg}$ vitamin C

For unknown sample:

Volume of required dye solution= Unknown sample

titration - Blank titration $=1.2-0.1=1.1 \mathrm{ml}$

Now,

$1 \mathrm{ml}$ dye solution is required for $=0.05291 \mathrm{mg}$ vitamin $\mathrm{C}$

$1.1 \mathrm{ml}$ dye solution is required for $=0.058201 \mathrm{mg}$ vitamin $\mathrm{C}$

Again,

$10 \mathrm{ml}$ vitamin $\mathrm{C}$ sample solution contains $=0.058201 \mathrm{mg}$

vitamin C

$100 \mathrm{ml}$ vitamin $\mathrm{C}$ sample solution contains $=0.58201 \mathrm{mg}$ vitamin C

Now,

$10 \mathrm{gm}$ raw carrot sample contains $=0.58201 \mathrm{mg}$ vitamin $\mathrm{C}$

$100 \mathrm{gm}$ raw carrot sample contains $=5.8201 \mathrm{mg}$ vitamin $\mathrm{C}=5.8 \%$

\subsection{For Cooked Carrot Sample}

Weight of cooked carrot sample (taken) $=10 \mathrm{gm}$

Total volume of cooked carrot sample $=100 \mathrm{ml}$

For cooked sample,

Volume of required dye solution $=$ Cooked sample titration

- Blank titration $=0.6-0.1=0.5 \mathrm{ml}$

Now,

$1 \mathrm{ml}$ dye solution is required for $=0.05291 \mathrm{mg}$ vitamin $\mathrm{C}$

$0.5 \mathrm{ml}$ dye solution is required for $=0.02645 \mathrm{mg}$ vitamin $\mathrm{C}$

Again,

$10 \mathrm{ml}$ vitamin $\mathrm{C}$ sample solution contains $=0.02645 \mathrm{mg}$ vitamin C

$100 \mathrm{ml}$ vitamin $\mathrm{C}$ sample solution contains $=0.2645 \mathrm{mg}$ vitamin $\mathrm{C}$
Now,

$10 \mathrm{gm}$ cooked carrot sample contains $=0.2645 \mathrm{mg}$ vitamin $\mathrm{C}$

$100 \mathrm{gm}$ cooked carrot sample contains $=2.645 \mathrm{mg}$ vitamin $\mathrm{C}=2.6 \%$

\section{Result \& Discussion}

The above experimental data shows the result of vitamin C content of fresh and cooked carrot. From the experimental value it is clear that the vitamin $\mathrm{C}$ content in carrot is decreased after heating.

From our research, we observed that vitamin $\mathrm{C}$ contained 5.8\% in raw carrot and after cooking the content of vitamin $\mathrm{C}$ is $2.6 \%$. From the observation we can say that the content of vitamin $\mathrm{C}$ is decreased with respect to cooking. So if we heat foods for long time, then the content of vitamin $\mathrm{C}$ is very low. As a result, this type of food is not benefited for growth our body.

We also observed that, the raw foods are contained more nutrient than that of the cooked foods. So the raw carrot contain more vitamin $\mathrm{C}$ then the cooked carrot.

\section{Conclusion}

On the basis of the results obtained from our investigation, the following statements may be drawn. Vitamin loss can be induced by a number of factors. Obviously, losses of vitamins depend on cooking time, temperature, and cooking method. Some vitamins are quite heat-stable, whereas others are heat-labile. Activity of vitamin C was generally destroyed by heat treatment of food, especially when there are traces of metals such as copper, but it is resistant to freezing. Vitamin $\mathrm{C}$ is probably one of the most unstable among the vitamins soluble in water. Raw carrots are taken for the estimation of nutrient constant. This is the standard value before cooking of carrot. After cooking the nutrient values were estimated and the changes of vitamin c were observed. Bangladesh is an under developing country and many people of this country are suffering from nutritional problem. For this reason people can choose fresh carrot or low cooked carrot to determine the values of nutrient or vitamin content are present in high amount. 


\section{References}

[1] F. Rose, The Wild Flower Key. London: Frederick Warne. p. 346, (2006).

[2] Why Fruits and Vegetables are Important FamilyEducation.com in http: life.familyeducation.com/foods/nutrition/36595.html

[7] J. Adubofuor, et al; Comparative study elated to physicochemicalproperties and sensory qualities of tomato juice and cocktail juice produced from ranges, tomatoes and carrots; African Journal of Food Science Vol. 4 (7), pp. 427-433, July 2010 .

[8] G. Vasanth Kumar, Ajay Kumar K. Raghu Patel G. R. and S. Manjappa; Determination of vitamin $\mathrm{C}$ in some fruits and vegetables in Davanagere city, (Karanataka) - India; Int. J. of Pharm. \& Life 2489-2491 2489, Sci. (IJPLS), Vol. 4, Issue 3: March: 2013.

[3] M. A. Masrizal, et al; Retention of Vitamin C, Iron, and BetaCarotene in Vegetables Prepared Using Different Cooking Methods. J Food Qual.; 20 (5): 403-418, (1997).

[4] N. C. Igwemmar, S. A. Kolawole, I. A. Imran; (IJSTR@2013); Effect Of Heating On Vitamin C Content Of Some Selected Vegetables; INTERNATIONAL JOURNAL OF SCIENTIFIC \& TECHNOLOGY RESEARCH; ISSN 2277-8616, VOLUME 2, ISSUE 11, NOVEMBER 2013.

[5] Pearson, 1973; Les4kova et al., 2003; Ball, 2006.

[6] M. Yahyaei, et al; The Effect of Different Methods of Heat Treatments on the Retention of Ascorbic Acid in Carrot and Corn; J. FBT, IAU, 3, 23-28, 2013.

[9] K. G. Masamba and M. Nguyen, Determination and comparison of vitamin $\mathrm{C}$, calcium and potassium in four selected conventionally and organically grown fruits and vegetables; African Journal of Biotechnology Vol. 7 (16), pp. 2915-2919, 18 August, 2008.

[10] AOAC (Association of Official Analytical Chemists), Official Method 985.33. 1990. Vitamin C (Reduced Ascorbic Acid) in Ready-to-feed Milk-based Infant Formula 2, 6Dichloroindophenol Titrimetric Method. 1108-1109. 